\title{
Mitochondrial alternative oxidase contributes to successful tardigrade anhydrobiosis
}

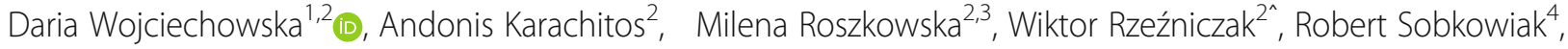 \\ Łukasz Kaczmarek ${ }^{3}$, Jakub Z. Kosicki ${ }^{5}$ and Hanna Kmita2 ${ }^{2}$
}

\begin{abstract}
Anhydrobiosis can be described as an adaptation to lack of water that enables some organisms, including tardigrades, to survive extreme conditions, even some that do not exist on Earth. The cellular mechanisms underlying anhydrobiosis are still not completely explained including the putative contribution of mitochondrial proteins. Since mitochondrial alternative oxidase (AOX), described as a drought response element in plants, was recently proposed for various invertebrates including tardigrades, we investigated whether AOX is involved in successful anhydrobiosis of tardigrades. Milnesium inceptum was used as a model for the study. We confirmed functionality of $M$. inceptum AOX and estimated its contribution to the tardigrade revival after anhydrobiosis of different durations. We observed that AOX activity was particularly important for $M$. inceptum revival after the long-term tun stage but did not affect the rehydration stage specifically. The results may contribute to our understanding and then application of anhydrobiosis underlying mechanisms.
\end{abstract}

Keywords: Anhydrobiosis, Mitochondrial alternative oxidase, Tardigrade, Milnesium inceptum

\section{Introduction}

Water availability is one of the most important factors for life. However, terrestrial habitats may endure occasional lack of water that requires specific adaptations from inhabiting organisms at different levels of biological organization. One of the most prevalent adaptations is anhydrobiosis, often called simply "life without water" [1-4]. The phenomenon is also known as desiccation tolerance, defined as the ability to dry to equilibrium with moderately to very dry air (i.e., to $10 \%$ water content or even less) and then recover to normal functioning after rehydration without sustaining damage [5]. A full explanation of the mechanisms underlying

\footnotetext{
* Correspondence: kmita@amu.edu.pl

Wiktor Rzeźniczak is deceased.

${ }^{2}$ Department of Bioenergetics, Institute of Molecular Biology and

Biotechnology, Faculty of Biology, Adam Mickiewicz University, Poznań, Poland

Full list of author information is available at the end of the article
}

anhydrobiosis and identification of biomarkers of successful anhydrobiosis may benefit different applications that rely on organism tolerance to extreme environmental conditions. Such applications could include, for example, dry vaccines, preservation of biological materials for transplantation or food production, enzymes working in a small amount of water and mechanisms of DNA protection and repair [4, 6-8].

Anhydrobiosis occurs in many microorganisms as well as in plants and some small invertebrates, and among the latter the best-known examples are tardigrades $[4,5,9-15]$. Tardigrade anhydrobiosis includes entering, permanent and leaving stages, which correspond to the dehydration (i.e., tun formation), tun and rehydration stages, respectively (e.g. [12]). In the tun stage a tardigrade is dehydrated and shrank to about $30 \%$ of its original volume, taking on a shape resembling a barrel via contraction of the anterior-posterior body axis, retraction of the legs and rearrangement of 
internal organs and cells. These changes are reversed during the rehydration stage $[2,10,12,13,16]$. Thus, on the organismal level, anhydrobiosis in tardigrades, is fairly well understood.

However, relevant molecular mechanisms are still not fully explained. Searching on the mechanisms has revealed several common components in anhydrobiotic animals. Accordingly, LEA proteins and heat shock proteins have been shown to be important for these animals' successful anhydrobiosis while other mechanisms are more prominent in some of these animals than others. For example Artemia shrimps and nematodes produce significant levels of trehalose to replace water as cells dehydrate, while some species of tardigrades produce none at all $[2,9,17,18]$. On the other hand, three families of intrinsically disordered proteins were identified only in tardigrades, namely the Cytoplasmic-, Secreted-, and Mitochondrial- Abundant Heat Soluble (CAHS, SAHS, and MAHS, respectively) proteins, collectively termed Tardigrade Disordered Proteins (TDPs). These proteins are highly expressed constitutively or significantly enriched in response to desiccation (e.g. [18, 19],) but seem to be missing in some tardigrades, suggesting that anhydrobiosis in tardigrades cannot be attributed solely to TDPs [20, 21]. However, available data appear to support a common and important role of proper mitochondria function in anhydrobiosis. Accordingly, it has been shown that mitochondria uncoupling abolishes tun formation [22], and the organelles contribute to tun functionality and successful rehydration [2325], but their role in tardigrade anhydrobiosis still remains elusive. Therefore, studies of mitochondrial proteins that are involved in surviving stress conditions should contribute to our understanding of the role of mitochondria in anhydrobiosis.

One of the mitochondrial proteins important in the response to drought stress is alternative oxidase (AOX) [26-29], the mitochondrial inner membrane, cyanideinsensitive, iron-binding protein that introduces a branch into the mitochondrial respiratory chain (MRC) at the coenzyme Q level. This allows for electron transfer from MRC complexes I and II via coenzyme Q to oxygen without involvement of the MRC cytochrome pathway composed of complexes III and IV [26, 29, 30]. As a result, AOX provides a bypath that releases constraints on the MRC cytochrome pathway and consequently participates in mitochondrial reductionoxidation reactions important for cell metabolic plasticity involved in adaptation to variable biotic and abiotic stress factors. Accordingly, heterologous expression of AOX in cultured mammalian cells, fruit flies and mice under mitochondrial stress conditions restores respiratory activity and corrects metabolism (e.g. [31]).
AOX was initially considered to be limited to plants as well as some fungi and protists but its presence has recently been proposed in different invertebrate animals, except for insects [28, 29, 31-33]. Analysis of available but scarce tardigrade genomic and/or transcriptomic data indicates the presence of AOX encoding gene in three tardigrade species [21, 28] including Milnesium inceptum [34] (formerly named Milnesium tardigra$d u m)$, known to be highly resistant to periodical dehydration under laboratory conditions (e.g., [17]). Thus, in this study we tested the hypothesis that AOX is involved in tardigrade anhydrobiosis using $M$. inceptum as a model for the research. To test this hypothesis, we verified the functionality of $M$. inceptum AOX and then estimated animals' recovery to full activity after dehydration or rehydration in the presence of an AOX inhibitor and after different durations of the tun stage. The results indicate that AOX activity is important for tun revival, as reflected by tardigrades' ability to return to full activity, but does not affect the rehydration stage itself. Additionally, the contribution of AOX depends on the duration of the tun stage.

\section{Materials and methods}

Detection of heterologously expressed $M$. inceptum AOX activity in mitochondria of intact Saccharomyces cerevisiae cells

For heterologous expression of $M$. inceptum AOX, the coding sequence of the protein was identified by bioinformatics methods (for details see electronic supplementary material, Figure S1 and Figure S2). The expression was performed by CRISPR/Cas 9 and $S$. cere-

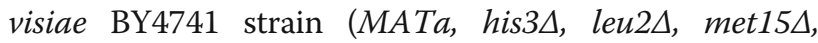
ura3A) (EUROSCARF) transformation by electroporation (for details see electronic supplementary material, Figure S3). Cells of the resulting BY4741 + AOX yeast

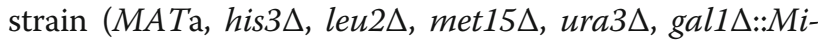
$A O X)$ were grown in YPG medium (1\% yeast extract, $2 \%$ peptone, $3 \%$ glycerol, $\mathrm{pH} 5.5)$ containing a nonfermentable carbon source that requires functioning mitochondria [35]. The cells were grown to $\mathrm{OD}_{550}=1$, then galactose at a final concentration of $2 \%$ was added to induce and maintain AOX expression for $24 \mathrm{~h}$. In parallel, control yeast cells were cultured in the absence of galactose. Then, yeast cells were washed twice with double distilled water $\left(\mathrm{ddH}_{2} \mathrm{O}\right)$, resuspended in $100 \mu \mathrm{L}$ of YPG and quantified by $\mathrm{OD}_{550}$ measurement. For the same amount of cells, rates of oxygen uptake were determined in $1 \mathrm{~mL}$ of YPG using a Clark electrode (Hansatech Instruments). To determine bioenergetics parameters related to AOX activity, $1 \mathrm{mM} \mathrm{KCN}$ (to inhibit the MRC complex IV, i.e., cytochrome c oxidase) and $3 \mathrm{mM}$ BHAM (to inhibit alternative oxidase) were applied. The applied final concentrations of $\mathrm{KCN}$ and 
BHAM were verified experimentally to achieve saturation.

\section{Detection of $M$. inceptum AOX presence in isolated $S$. cerevisiae mitochondria}

Mitochondria of $S$. cerevisiae cells expressing AOX were isolated according to the standard procedure [36]. Protein concentration was measured by the method of Bradford and albumin bovine serum (BSA), essentially fatty acid free, was used as a standard. The mitochondrial proteins were separated by SDS-PAGE in the presence of $6 \mathrm{M}$ urea and gels were stained with Coomassie Brilliant Blue G-250.

\section{Culture of $M$. inceptum}

The initial specimens of $M$. inceptum were collected in a xerothermic habitat: mosses on a concrete wall in the city centre of Poznań, Poland (52 $24^{\prime} 15^{\prime \prime} \mathrm{N}, 16^{\circ} 53^{\prime} 18^{\prime \prime} \mathrm{E}$, $87 \mathrm{~m}$ asl). The extraction was performed by the standard method [37]. To maintain the culture, $M$. inceptum specimens were kept at $18{ }^{\circ} \mathrm{C}$ in the darkness and at relative humidity (RH) of 40\% (POL EKO KK 115 TOP+ climatic chamber) in covered Petri dishes $(5.5 \mathrm{~cm}$ in diameter) with bottom scratched by sandpaper to allow tardigrade movements. Animals were coated with a thin layer of the culture medium being spring water (Żywiec Zdrój; Żywiec Zdrój S.A., Poland) mixed with $\mathrm{ddH}_{2} \mathrm{O}$ in 1:3 ratio. The culture medium was exchanged every week and the animals were fed with the nematode Caenorhabditis elegans Bristol N2 strain, and the rotifer Lecane inermis 1.A2.15 strain. The former was obtained from the Caenorhabditis Genetics Center at the University of Minnesota (Duluth, USA) and its culture was maintained by standard methods [38].

\section{$M$. inceptum anhydrobiosis protocol}

For tun formation, fully active (displaying coordinated movements of the body and legs) $M$. inceptum adult specimens of medium body length (approximately 500$550 \mu \mathrm{m})$ were extracted from the culture. After removal of debris, the animals were transferred to $3.5 \mathrm{~cm}$ (in diameter) covered and vented Petri dishes with bottom scratched by sandpaper. In each dish, 10 specimens were placed in $400 \mu \mathrm{l}$ of the culture medium and then dehydrated. Each of the experimental groups included four to six dishes. This denotes, for a total of 40-60 specimens per experimental group (Table 1). The dishes were allowed to dry slowly in the Q-Cell incubator (40-50\% $\mathrm{RH}, 20^{\circ} \mathrm{C}$, darkness) for $72 \mathrm{~h}$. Tun formation was checked once per $24 \mathrm{~h}$ period by a short observation (about $1 \mathrm{~min}$ ) under an Olympus SZ61 stereomicroscope connected to an Olympus UC30 microscope digital camera. The dehydrated animals (tuns) were kept under the above conditions for 3, 30 or 60 days.

After 3, 30 or 60 days of the tun stage duration, the tun rehydration was performed by addition of $3 \mathrm{ml}$ of the culture medium to each dish, and the tuns were transferred to small glass cubes and kept at room conditions ( 18 to $20^{\circ} \mathrm{C}, 40-50 \% \mathrm{RH}$ and light conditions regulated by seasonal changes in day/night cycle; it should be mentioned that according to our observations, photoperiod does not affect return of $M$. inceptum tuns to active life). The animals' return to full activity was observed in the glass cubes at chosen time points (i.e., time windows: 10, 20, 30, 40, 60, 90, 120, 180, 240, 360, 480 and $1440 \mathrm{~min}$ ) for approximately $1 \mathrm{~min}$ under the stereomicroscope. The average number of specimens that recovered to full activity after $24 \mathrm{~h}$ (1440 min) from the onset of rehydration was defined as the final return to full activity.

BHAM, a known AOX inhibitor (prepared in methanol), and MitoTEMPO, a known mitochondria-specific superoxide scavenger (prepared in $\mathrm{dd}_{2} \mathrm{O}$ ), were added to the culture medium at the beginning of the dehydration or rehydration stage. The applied final concentrations of BHAM (0.1 and $0.2 \mathrm{mM})$ and MitoTEMPO $(0.01 \mathrm{mM})$ were verified experimentally to avoid lethal effect. For that, we analysed animal mobility after addition of the compounds to the culture medium containing active animals. We assumed the absence of a lethal effect when approximately $90 \%$ of the treated animals moved their legs and body in a coordinated way $24 \mathrm{~h}$ after addition of the compounds. Because two different solvents were applied for BHAM and

Table 1 Experimental groups applied in the studies. They included two different concentrations of BHAM during M. inceptum dehydration and rehydration, and one concentration of MitoTEMPO during $M$. inceptum dehydration (including proper controls) as well as different durations of the tun stage. The tested conditions are marked with the $x$

\begin{tabular}{|c|c|c|c|c|c|c|c|c|}
\hline \multirow{3}{*}{$\begin{array}{l}\text { TUN } \\
\text { DURATION } \\
\text { (days) }\end{array}$} & \multicolumn{8}{|c|}{ EXPERIMENTAL GROUPS } \\
\hline & \multicolumn{5}{|l|}{ DEHYDRATION } & \multicolumn{3}{|l|}{ REHYDRATION } \\
\hline & $\begin{array}{l}\text { control } 1 \\
(0.3 \% \mathrm{v} / \mathrm{v} \text { methanol })\end{array}$ & $\begin{array}{l}0.1 \mathrm{mM} \\
\text { BHAM }\end{array}$ & $\begin{array}{l}0.2 \mathrm{mM} \\
\text { BHAM }\end{array}$ & $\begin{array}{l}\text { control } 2 \\
\text { (culture medium) }\end{array}$ & $\begin{array}{l}0.01 \mathrm{mM} \\
\text { MitoTEMPO }\end{array}$ & $\begin{array}{l}\text { control } 1 \\
(0.3 \% \mathrm{v} / \mathrm{v} \text { methanol })\end{array}$ & $\begin{array}{l}0.1 \mathrm{mM} \\
\text { BHAM }\end{array}$ & $\begin{array}{l}0.2 \mathrm{mM} \\
\text { BHAM }\end{array}$ \\
\hline 3 & $x$ & $x$ & $x$ & $x$ & $x$ & $x$ & $x$ & $x$ \\
\hline 30 & $x$ & $x$ & $x$ & & & & & \\
\hline 60 & $x$ & $x$ & $x$ & $x$ & $x$ & $x$ & $x$ & $x$ \\
\hline
\end{tabular}


MitoTEMPO, two different controls were used in experiments: control $1\left(C_{1}\right)$ included animals dehydrated or rehydrated in the culture medium in the presence of suitably diluted methanol solution $(0.3 \% \mathrm{v} / \mathrm{v})$, and control $2\left(\mathrm{C}_{2}\right)$ included animals dehydrated in the culture medium. To test for differences in the animals' return to full activity, we compared the animals' recovery at the applied time windows $(10,20,30,40,60,90,120,180$, 240, 360, 480 and $1440 \mathrm{~min}$ ) between experimental groups (Table 1) and for different time spent in the tun stage. For animals treated with BHAM, during both dehydration and rehydration, we distinguished three experimental groups $\left(C_{1}, 0.1 \mathrm{mM}\right.$ BHAM and $0.2 \mathrm{mM}$ BHAM) and for animals treated with MitoTEMPO during dehydration, we distinguished two experimental groups $\left(\mathrm{C}_{2}\right.$ and $0.01 \mathrm{mM}$ MitoTEMPO).

\section{Chemicals}

Manufacturers of the chemicals used are listed in electronic supplementary material, Table S1.

\section{Statistical analysis}

Effects of BHAM and $\mathrm{KCN}$ on the rate of oxygen uptake displayed by $S$. cerevisiae cells were analysed by $t$-test.

For testing differences in number of tuns formed under different conditions (in the presence of MitoTEMPO or BHAM as well as for proper controls) oneway ANOVA [39] was applied.

To analyse the effect of BHAM presence during tun formation or rehydration and of MitoTEMPO presence during tun formation on anhydrobiotic animals' recovery to full activity after different duration of the tun stage, Factorial ANOVA [39] was applied. For this analysis we used two grouping independent variables: (I) time windows of animal observations following rehydration and (II) the applied compound concentrations. The latter denotes two different concentrations of BHAM versus control conditions and one concentration of MitoTEMPO versus control conditions, where control conditions denote the absence of BHAM or MitoTEMPO. In this way we distinguished three experimental groups for testing of BHAM presence $\left(\mathrm{C}_{1}, 0.1 \mathrm{mM}\right.$ BHAM and 0.2 mM BHAM) or two experimental groups for testing of the MitoTEMPO $\left(\mathrm{C}_{2}\right.$ and $0.01 \mathrm{mM}$ MitoTEMPO) (Table $1)$. Thus, differences in animals' return to full activity were tested between the mentioned two grouping independent variables: (I) 12 time windows $(10,20,30,40$, $60,90,120,180,240,360,480$ and $1440 \mathrm{~min}$ ) and (II) three experimental groups distinguished for BHAM $\left(\mathrm{C}_{1}\right.$, $0.1 \mathrm{mM}$ BHAM and $0.2 \mathrm{mM}$ BHAM) or (III) two experimental groups distinguished for MitoTEMPO $\left(\mathrm{C}_{2}\right.$ and $0.01 \mathrm{mM}$ MitoTEMPO). Because of the application of the two grouping variables, it was impossible to simply test the differences between each group, as the effect of multiple comparisons would decrease the biological value of the results [40]. We used the standard presentation of results for Factorial ANOVA analysis [39, 40]. For each model we calculated $F$-statistics and $\mathrm{R}^{2}$ as a measure of variance explained [40]. For ANOVA models, when $F$ was statistically significant (i.e., $\alpha$ probabilities $(p)<0.05)$, in the next step we deepened that analysis by determination of statistically significant factors in the model (i.e., time window or experimental groups). For this purpose we performed $t$-test for each independent variable (electronic supplementary material, Table S2 and Table S3). If this test for the factor 'experimental groups' was statistically significant, it provided (from a methodical point of view) an authorization to perform Tukey post-hoc test [39]. Then the post-hoc test results were visualized in figures.

To compare effects of BHAM and MitoTEMPO on animals' return to full activity, we analysed the ratios of average numbers of fully active animals obtained for BHAM- or MitoTEMPO-treated tardigrades to average numbers of fully active appropriate control animals for different duration of the tun stage. The analysis was performed, regardless of the time windows, using developed Linear Mixed Models for the duration of the tun stage (3 and 60 days) and the applied concentrations of BHAM $(0.1 \mathrm{mM}$ and $0.2 \mathrm{mM})$ and MitoTEMPO $(0.01 \mathrm{mM})$. This procedure was justified by our observation that revival time was influenced by the time window (see Results). To control for that factor we developed models with time window as a random factor and concentration as a fixed effect. All calculations were performed using R [41].

\section{Results}

The predicted $M$. inceptum AOX is a functional protein

The performed bioinformatics analysis indicated that the predicted M. inceptum AOX displayed a set of properties expected for animal AOX [32, 33]. The predicted protein could be imported into the inner mitochondrial membrane, could form the postulated tertiary structure, and contained the ferritin-like domain and a characteristic motif at the C-terminus defined as a marker of animal AOX (electronic supplementary material, Figure S1 and S2). To functionally assess $M$. inceptum AOX, the predicted protein was expressed in S. cerevisiae cells for $24 \mathrm{~h}$ under galactose control. Then cell respiration, (i.e., the rate of oxygen uptake) was estimated, and the effects of known inhibitors of AOX (BHAM) and the cytochrome c oxidase (MRC complex IV) representing the MRC cytochrome pathway (KCN) were determined. In the absence of $M$. inceptum AOX expression (Fig. 1A), yeast cell respiration was inhibited by $1 \mathrm{mM} \mathrm{KCN}$ but not by $3 \mathrm{mM}$ BHAM, independently of the order of their additions. In the presence of $M$. inceptum AOX expression (Fig. 1B), the inhibitory effect of $\mathrm{KCN}$ was distinctly 

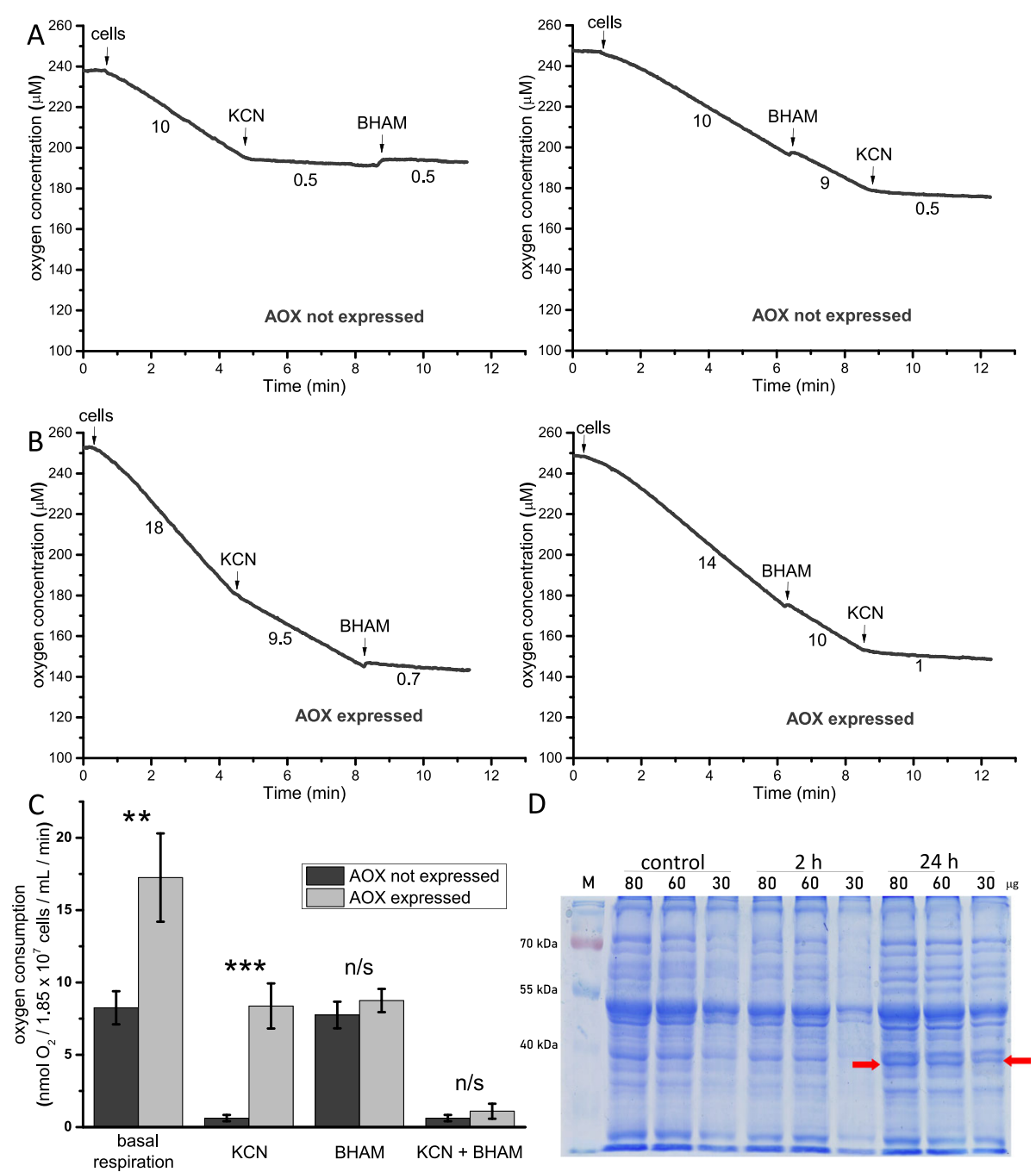

Fig. 1 Functional analysis of $M$. inceptum AOX expressed in S. cerevisiae mitochondria. Tardigrade AOX expression was induced by the addition of galactose to YPG medium. (a) and (b) Representative traces of the performed measurements of the rate of oxygen uptake by intact yeast cells in the absence (AOX not expressed) and in the presence (AOX expressed) of galactose. (c) Changes in S. cerevisiae cell respiration in the presence or the absence of AOX expression and after addition of inhibitors of AOX (BHAM) and MRC complex IV (KCN). The applied concentrations of inhibitors were as follows: $1 \mathrm{mM} \mathrm{KCN}$ and $3 \mathrm{mM}$ BHAM. ${ }^{* *} p<0.01$; ${ }^{* *} p<0.001 ; \mathrm{n} / \mathrm{s}$ not statistically significant. (d) Detection of $M$. inceptum AOX expression and maintenance in $S$. cerevisiae mitochondria in the presence of galactose. Mitochondria were isolated from cells cultured in the absence of galactose (control) and in its presence, after 2 and $24 \mathrm{~h}$. The red arrows indicate bands corresponding to M. inceptum AOX

diminished and the resulting $\mathrm{KCN}$-resistant respiration was sensitive to BHAM. Importantly, BHAM-sensitive respiration was also observed before $\mathrm{KCN}$ addition. As shown in Fig. 1C, respiration of S. cerevisiae cells not expressing $M$. inceptum AOX was sensitive to $\mathrm{KCN}$ but not to BHAM, whereas respiration of yeast cells expressing $M$. inceptum AOX was sensitive to BHAM and only partially to KCN. Moreover, basal respiration of S. cerevisiae cells expressing $M$. inceptum AOX was approximately two times higher than that of cells not expressing $M$. inceptum AOX but the difference was eliminated by addition of BHAM. Accordingly, as shown in Fig. 1D, only mitochondria isolated from yeast cells cultured in the presence of galactose, triggering AOX expression, contained distinct amounts of a protein of molecular weight close to $40 \mathrm{kD}$, which corresponds to the molecular weight of heterologously expressed animal AOX proteins [42].

\section{The presence of BHAM during tun formation but not during tun rehydration affects $M$. inceptum recovery to full activity}

As expected (e.g., [15]), for the studied duration of the tun stage, (i.e., 3, 30 and 60 days; Fig. 2A - C, respectively) tardigrade revival, corresponding to return to full activity, was delayed as the tun stage duration extended. 

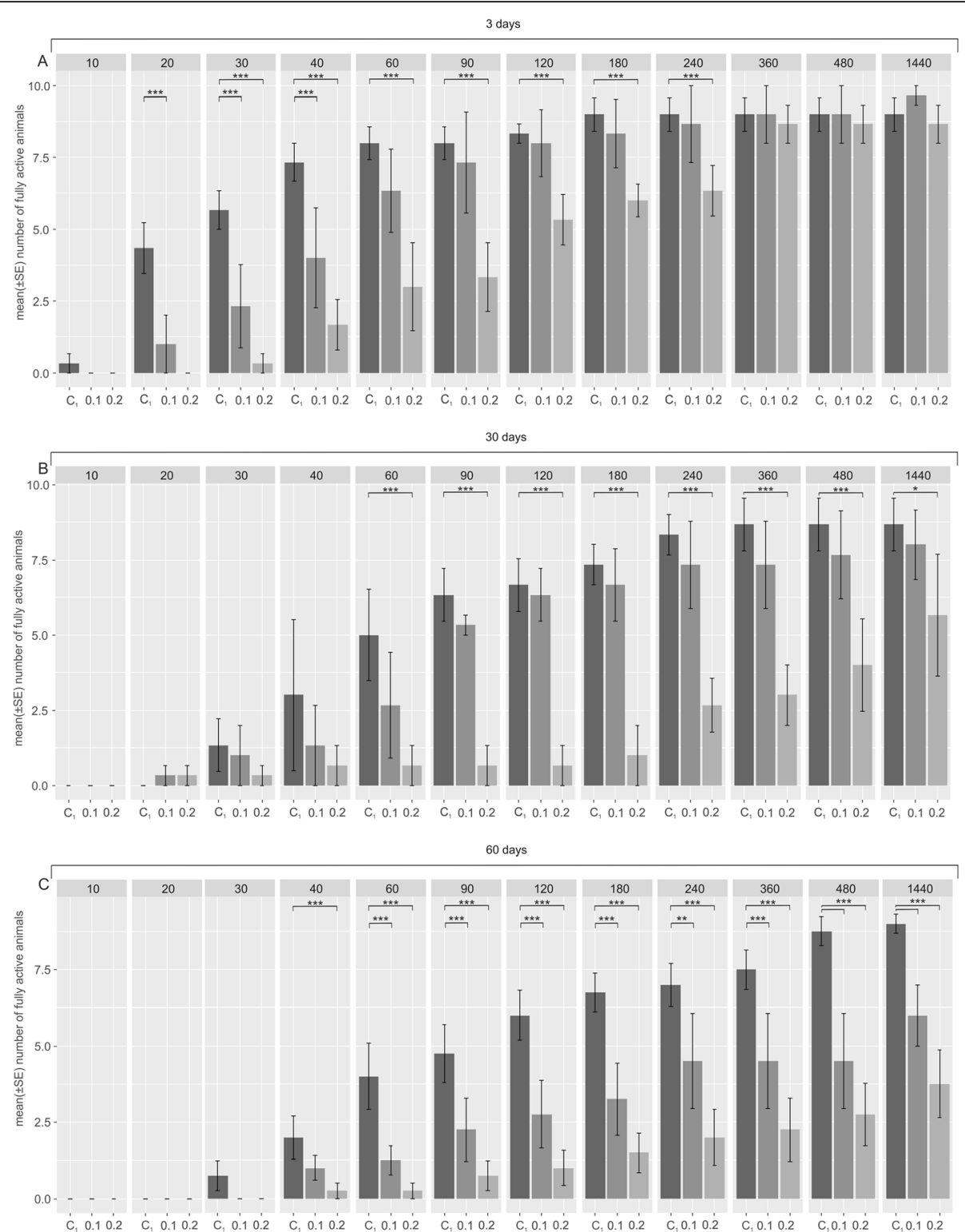

Fig. 2 The effect of BHAM presence during M. inceptum tun formation on return to full activity. (a), (b) and (c) Tun duration for 3, 30 and 60 days, respectively. Full activity was defined as coordinated movements of animal body and legs (crawling). The time windows of observations are indicated in minutes following the onset of rehydration. $C_{1}$, control 1 ( $0.3 \%$ methanol in the culture medium); 0.1 and 0.2 , two different BHAM concentrations (i.e., 0.1 and $0.2 \mathrm{mM} \mathrm{BHAM}$, respectively). ${ }^{*} p<0.05$; ${ }^{* *} p<0.01$; ${ }^{* *} p<0.001$ (see also electronic supplementary material, Table S2)

The presence of 0.1 or $0.2 \mathrm{mM}$ BHAM during tun formation additively affected the return to full activity in a manner that was dependent on BHAM concentration. Since the $t$-test for the factor "experimental groups" (i.e. control 1, $1 \mathrm{mM}$ BHAM and $0.2 \mathrm{mM}$ BHAM) was statistically significant, the Tukey post-hoc test was developed to test differences between (I) control 1 vs. $0.1 \mathrm{mM}$ BHAM and (II) control 1 vs. $0.2 \mathrm{mM}$ BHAM for different duration of the tun stage (Fig. 2 and electronic supplementary material, Table S2). After the tun stage lasting 3 days (Fig. 2A) statistically significant delay was observed in return to full activity, especially for the higher BHAM concentration, although the final return to full activity was comparable to that of the control group. However, the final return to full activity was distinctly decreased for the tun stage formed in the presence of BHAM and lasting 30 and 60 days. In the case of the former (30 days) a statistically significant decrease was observed only for $0.2 \mathrm{mM} \mathrm{BHAM} \mathrm{(Fig.} \mathrm{2B),} \mathrm{whereas}$ in the case of the latter (60 days), a statistically significant decrease was observed for both BHAM concentrations, and the decrease was more pronounced for 0.2 
mM BHAM (Fig. 2C). Thus, the duration of the tun stage as well as the presence of BHAM during tun formation had statistically significant additive effects on return to full activity, which also depended on the AOX inhibitor concentration.

When added during rehydration, $0.1 \mathrm{mM}$ or $0.2 \mathrm{mM}$ BHAM did not influence return to full activity in a statistically significant way after the tun stage of any duration (Fig. 3 and electronic supplementary material, Table S2). Thus, the presence of BHAM during tun rehydration appeared to not affect animals' return to full activity.

\section{BHAM and MitoTEMPO applied during tun formation have different effects on $M$. inceptum recovery to full activity}

MitoTEMPO is a well-known mitochondria-specific superoxide scavenger. Since this activity is also suggested for hydroxamic acids, including BHAM [43, 44], we checked the effect of MitoTEMPO presence during tun formation on animals' return to full activity. For the studied duration of the tun stage ( 3 and 60 days), the presence of MitoTEMPO during tun formation did not affect the return to full activity in a statistically significant way (Fig. 4 and electronic supplementary materials, Table S3).

Nevertheless, comparison of effects imposed by the presence of MitoTEMPO or BHAM during tun formation (Fig. 5 and electronic supplementary material, Table S4) indicated that animals forming tuns in the presence of MitoTEMPO displayed faster return to full activity than animals forming tuns in the presence of BHAM. Furthermore, the BHAM effect was distinctly dependent on its concentration and the tun stage duration. Thus, the effects of BHAM and MitoTEMPO imposed during tun formation and exerted on tardigrade recovery to full activity were different. That observation suggested that the effect of BHAM is based on different mechanisms than that of MitoTEMPO. It should be also mentioned that the average number of $M$. inceptum tuns with the expected appearance [16] was not changed by their formation in the presence of BHAM and MitoTEMPO (electronic supplementary material, Fig. S4).
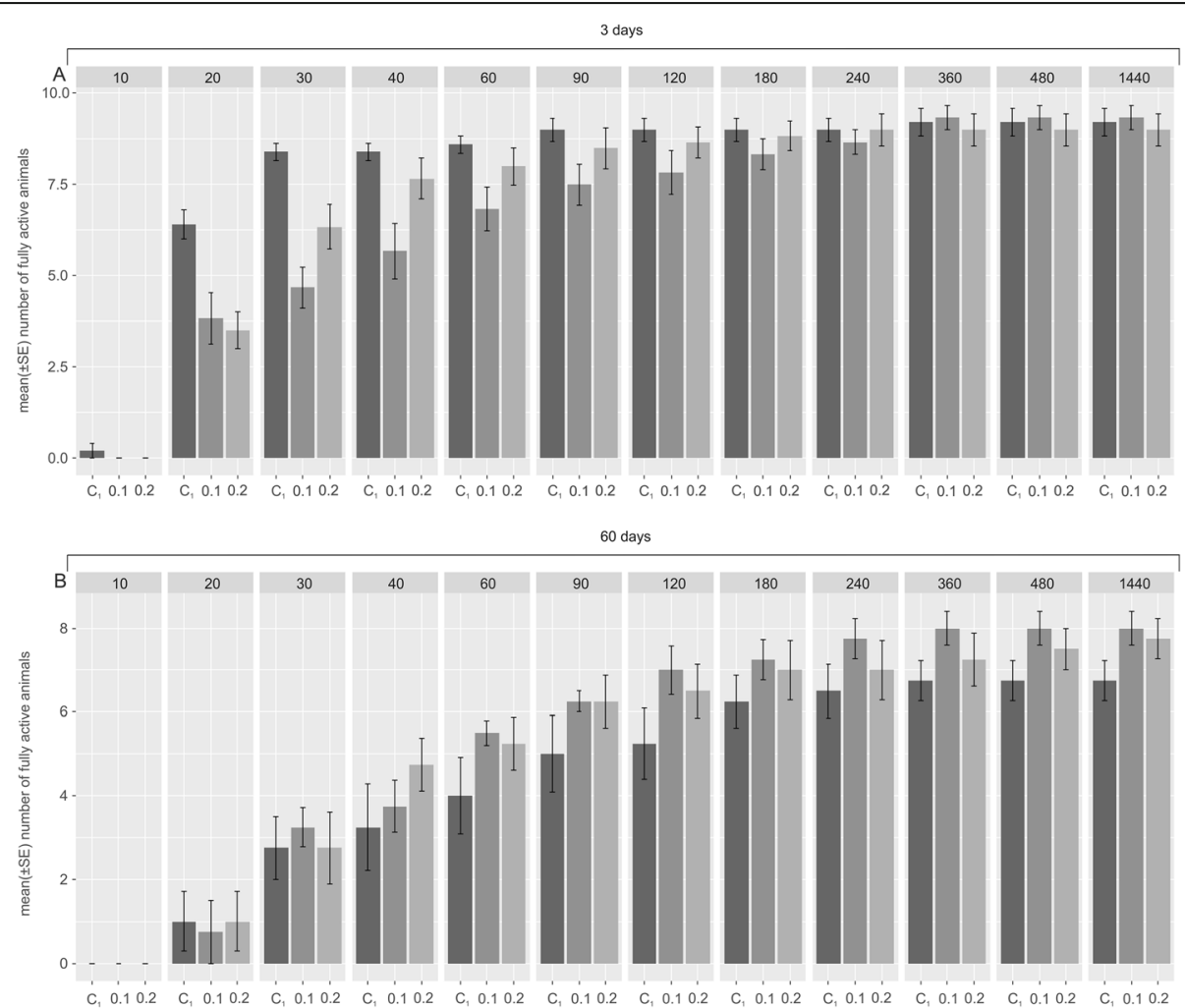

Fig. 3 The effect of BHAM presence during M. inceptum tun rehydration on return to full activity. (a) and (b) Tun duration for 3 and 60 days, respectively. Full activity was defined as coordinated movements of animal body and legs (crawling). The time windows of observations are indicated in minutes following the onset of rehydration. $C_{1}$, control 1 ( $0.3 \%$ methanol in the culture medium); 0.1 and 0.2 , two different BHAM concentrations (i.e., 0.1 and $0.2 \mathrm{mM} \mathrm{BHAM}$, respectively). The differences observed for the mentioned experimental groups were not statistically significant (see also electronic supplementary material, Table S2) 

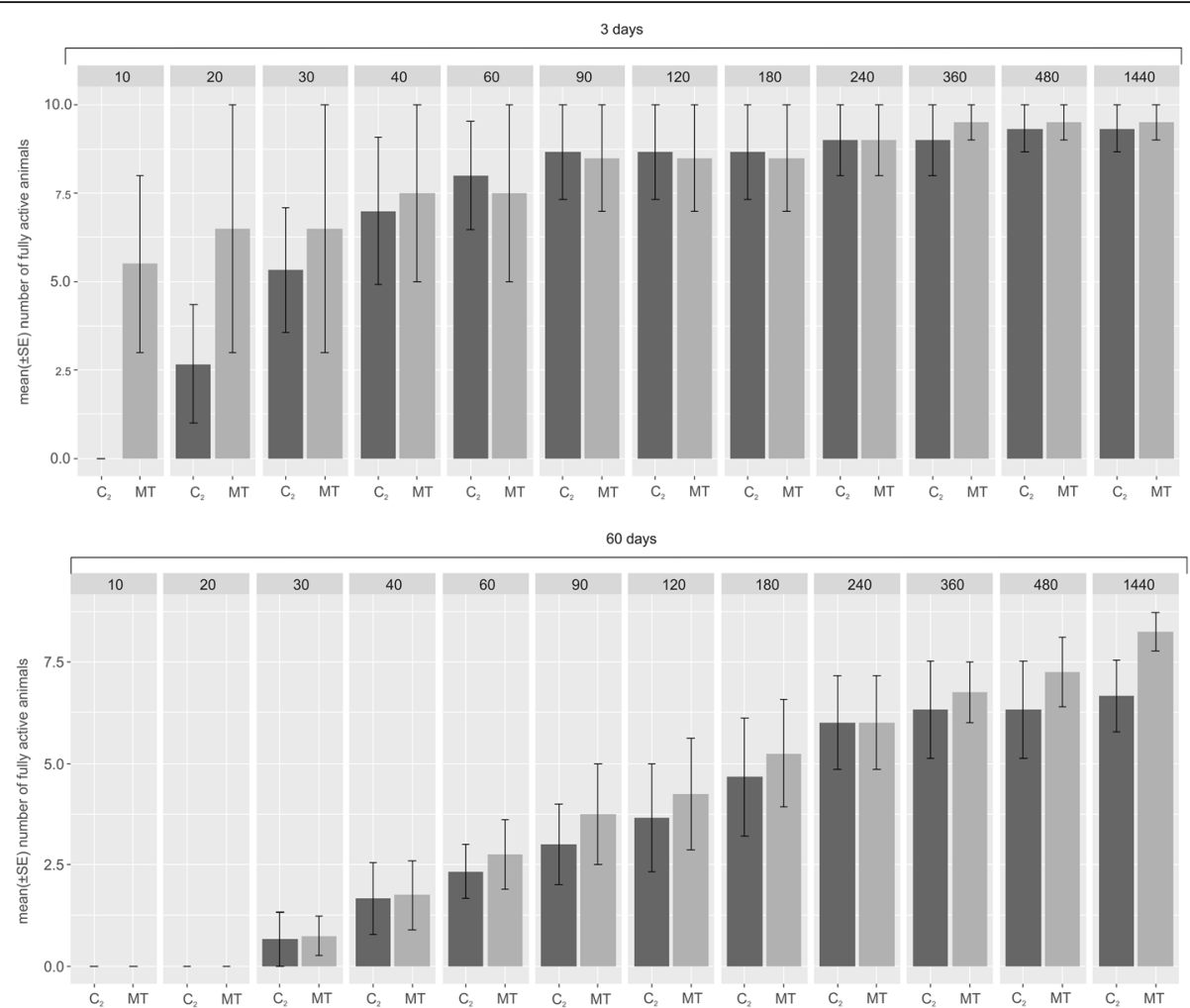

Fig. 4 The effect of MitoTEMPO presence during M. inceptum tun formation on return to full activity. (a) and (b) Tun duration for 3 and 60 days, respectively. Full activity was defined as coordinated movements of animal body and legs (crawling). The time windows of observations are indicated in minutes following the onset of rehydration. $C_{2}$, control (the culture medium); MT, $0.01 \mathrm{mM}$ MitoTEMPO. The differences observed for the mentioned experimental groups were not statistically significant (see also electronic supplementary material, Table S3)

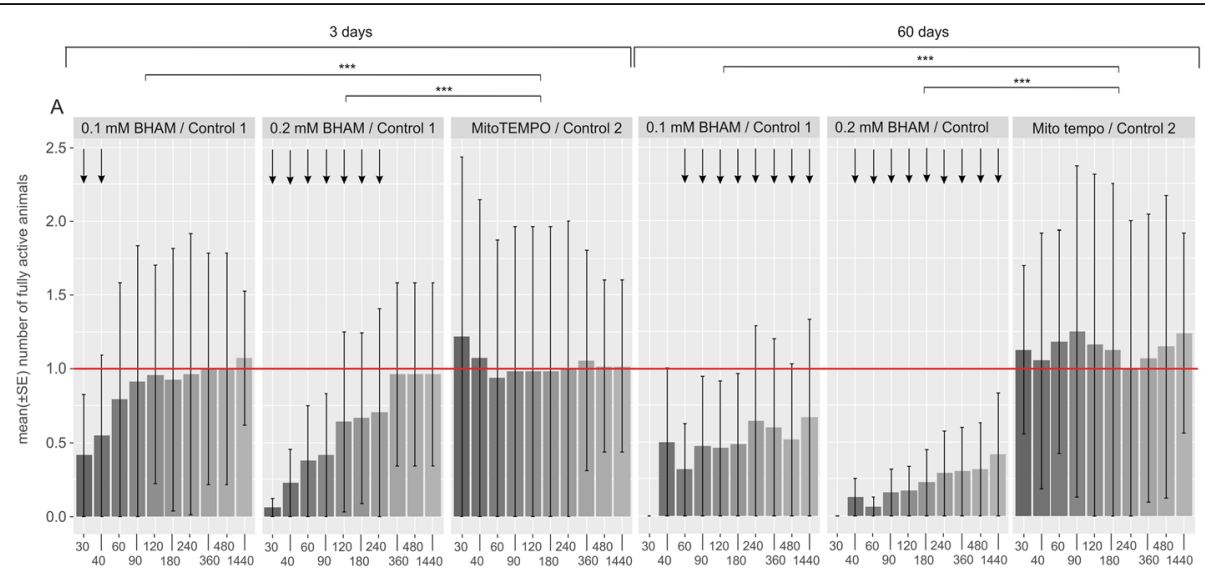

Fig. 5 Comparison of the effect of the presence of BHAM and MitoTEMPO during M. inceptum tun formation on return to full activity. For the comparison, ratios between fully active animals treated with BHAM $(0.1$ or $0.2 \mathrm{mM})$ or MitoTEMPO $(0.01 \mathrm{mM})$ and proper control animals were calculated and analysed by application of the developed Linear Mixed Models (see electronic supplementary material, Table S4). The analysis was performed for different duration of the tun stage. The time windows of observations are indicated in minutes following the onset of rehydration. Full activity was defined as coordinated movements of animal body and legs (crawling). control 1, 0.3\% methanol in the culture medium; control 2, the culture medium. ${ }^{* * *} p<0.001$ (see also Tab. S4). Arrows indicate statistically significant differences between the experimental groups, shown also in Fig. 2 


\section{Discussion}

Here we provide data on functionality of the tardigrade $M$. inceptum AOX and its possible contribution to the animal anhydrobiosis. The presence of functional AOX in the tardigrade mitochondria was confirmed bioinformatically (electronic supplementary material, Fig. S1 and S2) and experimentally by heterologous expression of the protein in S. cerevisiae cells. As shown in Fig. 1, M. inceptum AOX conferred KCN-resistant and AOX inhibitorsensitive respiration to $S$. cerevisiae cells. The analogous observation was reported for the pacific oyster Crassostrea gigas AOX heterologously expressed in yeast mitochondria [42]. Similarly, heterologous expression of the tunicate Ciona intestinalis AOX enables in vivo $\mathrm{KCN}$ tolerance in Drosophila melanogaster [45] and mice [46, 47], observed also for the isolated mitochondria [45-47]. However, in mouse and D. melanogaster mitochondria, the enzyme became enzymatically active only when the MRC cytochrome pathway was inhibited beyond coenzyme Q [31, 47-49], whereas in S. cerevisiae mitochondria the activity was observed without the cytochrome pathway inhibition [42]. The data available for C. gigas AOX studied in the oyster isolated mitochondria do not allow conclusions about the underlying mechanisms [50]. Nevertheless, the data on C. gigas AOX expressed in S. cerevisiae mitochondria [42] correspond to $M$. inceptum AOX based respiration of $S$. cerevisiae cells (Fig. 1). The difference in regulation of animal AOX in $S$. cerevisiae and animal mitochondria can be explained by differences in organization of the animal and S. cerevisiae MRC, including complex I which precedes coenzyme $\mathrm{Q}$ in animal MRC but is absent in S. cerevisiae mitochondria [51]. Accordingly, it has recently been shown that in the absence of the MRC cytochrome pathway inhibitors, respiratory activity of complex II, but not complex I, both providing electrons to coenzyme $\mathrm{Q}$, is a pre-requisite for the engagement of AOX activity [31].

The engagement could result in coenzyme Q oxidation and consequently diminution of Reactive Oxygen Species (ROS) generation providing damages to DNA, proteins and phospholipids [52-54]. Thus, the enzyme may be considered an important element of protection against ROS-mediated oxidative stress indicated for anhydrobiosis. Oxidative stress can occur during tun formation (dehydration) and tun rehydration $[2,15,55]$ due to different mechanisms. During dehydration oxidative stress may result from gradual elimination of water and deprivation of appropriate oxygen availability [2], whereas during rehydration, it may be triggered by reoxygenation [56] and reverse electron transport [28, 57]. Moreover, it is suggested that the decline in revival with increasing time in the tun stage may be caused by oxidative stress based on non-enzymatic and/or enzymatic reactions [2, 15, 58]. Accordingly, in $M$. inceptum, the amount of oxidative DNA damage increases with duration of the tun stage [59]. Thus, if the tardigrade AOX contributes to protection against oxidative stress, the protection should be distinctly impaired in the presence of AOX inhibitor (e.g., BHAM).

The impact of BHAM presence during tun formation on return to full activity by anhydrobiotic $M$. inceptum specimens appears to suggest that AOX has an important role during dehydration (Fig. 2) but not during rehydration (Fig. 3). Moreover, tun formation in the presence of BHAM enhanced the well-known effect of the tun stage duration on anhydrobiotic tardigrade recovery to full activity $[12,15,60]$. We observed that the duration of the tun stage as well as the presence of BHAM during tun formation had additive effects on animals' return to full activity in a BHAM concentrationdependent manner. Therefore, it may be assumed that AOX contributes to anti-oxidative protection systems underlying dehydration tolerance. Thus, AOX inhibition could impair anti-oxidative protection and, consequently, tardigrade revival.

However, the question arises whether the AOX contribution is more pronounced during dehydration or during the tun stage itself. Taking into account that the presence of BHAM, independently of the applied concentration, did not impair the average number of formed tuns (electronic supplementary material, Fig. S4), one could assume that the activity of AOX is important during the tun stage. Consequently, AOX impairment caused by its inhibitor would result in additional impairment of revival after the tun stage, illustrated by the delay in return to full activity and/or the decreased final return to full activity. Since we observed such an effect of BHAM presence, with revival being dependent on the inhibitor concentration and the tun stage duration (Fig. 2), we assume that AOX contributes to M. inceptum tun revival and that its contribution increases with the tun stage duration. As mentioned above, the duration of the tun stage correlates with the possibility of oxidative damage occurrence [59]. One could ask how it is possible for AOX to be active in the nearly complete absence of water. As summarized in [18], water replacement, vitrification (i.e., biological glass formation) and molecular shielding are putative mechanisms enabling dehydration survival. They probably overlap and probably synergistically promote dehydration tolerance that might be based on activity of some proteins. Accordingly, it is suggested that in the presence of some polar molecules including glycerol or trehalose, cells are able to simulate the types of molecular interactions (like hydrogen bonding) that would occur in water [61].

The apparent role of AOX in long-term anhydrobiosis can be explained by its commonly mentioned anti- 
oxidative effect. BHAM itself may also display such an activity [43, 44], but our data indicate that the effect observed for BHAM (Fig. 2) differs distinctly from that imposed by MitoTEMPO, a well-known mitochondriaspecific superoxide scavenger (Figs. 4 and 5). This, in turn, implies that AOX contribution is much more complex. On the one hand, AOX may ensure efficient ATP synthesis under constrained activity of the MRC cytochrome pathway. The possibility of ATP synthesis appears to be pertinent for successful aestivation [62], an important animal survival strategy that, like anhydrobiosis, requires reversible transitions to and from hypometabolic states [63]. On the other hand, AOX may contribute to the control of ROS generation by MRC modulation, also in invertebrate cells $[46,64]$. Thus, the obtained results confirm the importance of AOX research in explaining the role of mitochondria in successful anhydrobiosis that may have application in medicine, biotechnology and even space travels.

\section{Supplementary Information}

The online version contains supplementary material available at https://doi. org/10.1186/s12983-021-00400-5.

Additional file 1: Table S1. Manufacturers of chemicals applied in the studies. Table S2. Results of Factorial ANOVA. Table S3. Results of Factorial ANOVA. Table S4. Results for Linear Mixed Models developed to compare effects of BHAM and MitoTEMPO on animals' return to full activity after the tun stage of different duration. Figure S1.

Bioinformatics analysis of the putative $M$. inceptum AOX amino acid sequence. Figure S2. Bioinformatic identification of M. inceptum AOX. Figure S3. Integration of the AOX gene into the yeast genome. Figure S4. The average numbers of tuns formed by $M$. inceptum specimens in the absence and in the presence of BHAM and MitoTEMPO.

\section{Acknowledgements}

The studies were performed partly in the framework of activities of BARg (Biodiversity and Astrobiology Research group). We would like to thank Edyta Fiałkowska (Jagiellonian University in Kraków, Poland) for Lecane inermis cultures, Pushpalata Kayastha (Adam Mickiewicz University in Poznań, Poland) for help in identification of the applied tardigrade species and Felix Bemm (Max Planck Institute for Developmental Biology, Tübingen, Germany) for data concerning the $M$. inceptum AOX encoding gene.

\section{Authors' contributions}

D.W., M.R., R.S. and Ł.K. performed anhydrobiosis studies; A.K. and W.R. performed bioinformatics and bioenergetics analysis; H.K., D.W. and J.K. analysed the data with input from $Ł . K$. and A.K.; all authors participated in the study design and manuscript writing. The author(s) read and approved the final manuscript.

\section{Funding}

The studies were supported by a research grant of the National Science Centre, Poland (NCN 2016/21/B/NZ4/00131).

\section{Availability of data and materials}

They will be deposited on an open-access platform.

\section{Declarations}

Ethics approval and consent to participate

The described studies do not require approval from ethical committees.
Consent for publication

No consents are required.

\section{Competing interests}

The authors declare that no competing interests exist.

\section{Author details}

${ }^{1}$ Department of Macromolecular Physics, Faculty of Physics, Adam Mickiewicz University, Poznań, Poland. ${ }^{2}$ Department of Bioenergetics, Institute of Molecular Biology and Biotechnology, Faculty of Biology, Adam Mickiewicz University, Poznań, Poland. 'Department of Animal Taxonomy and Ecology, Institute of Environmental Biology, Faculty of Biology, Adam Mickiewicz University, Poznań, Poland. ${ }^{4}$ Department of Cell Biology, Institute of Experimental Biology, Faculty of Biology, Adam Mickiewicz University, Poznań, Poland. ${ }^{5}$ Department of Avian Biology and Ecology, Institute of Experimental Biology, Faculty of Biology, Adam Mickiewicz University, Poznań, Poland

Received: 23 February 2021 Accepted: 15 March 2021

Published online: 01 April 2021

\section{References}

1. Watanabe M. Anhydrobiosis in invertebrates. Appl Entomol Zool. 2006;41(1): 15-31. https://doi.org/10.1303/aez.2006.15

2. Rebecchi L. Dry up and survive: the role of antioxidant defences in anhydrobiotic organisms. J Limnol. 2013;72(Suppl. 1):62-72. https://doi org/10.4081/jlimnol.2013.s1.e8.

3. Arakawa K, Blaxter M. Life without water. Biochemist. 2017;39(6):14-7. https://doi.org/10.1042/BIO03906014.

4. Kaczmarek $Ł$, Roszkowska M, Fontaneto D, Jezierska M, Pietrzak B, Wieczorek $\mathrm{R}$, et al. Staying young and fit? Ontogenetic and phylogenetic consequences of animal anhydrobiosis. J Zool. 2019;309(1):1-11. https://doi. org/10.1111/jzo.12677.

5. Alpert P. Constraints of tolerance: why are desiccation-tolerant organisms so small or rare? J Exp Biol. 2006;209(9):1575-84. https://doi.org/10.1242/jeb.02179.

6. Schill RO, Mali B, Dandekar T, Schnolzer M, Reuter D, Frohme M. Molecular mechanisms of tolerance in tardigrades: new perspectives for preservation and stabilization of biological material. Biotechnol Adv. 2009;27(4):348-52. https://doi.org/10.1016/j.biotechadv.2009.01.011.

7. Guidetti R, Rizzo AM, Altiero T, Rebecchi L. What can we learn from the toughest animals of the earth? Water bears (tardigrades) as multicellular model organisms in order to perform scientific preparations for lunar exploration. Planet Space Sci. 2012;74(1):97-102. https://doi.org/10.1016/j. pss.2012.05.021.

8. Ono F, Mori Y, Takarabe K, Fujii A, Saigusa M, Matsushima Y, et al. Effect of ultra-high pressure on small animals, tardigrades and Artemia. Cogent Phys. 2016;3(1):1. https://doi.org/10.1080/23311940.2016.1167575.

9. Crowe $\mathrm{JH}$. The physiology of cryptobiosis in tardigrades. Mem Ist Ital Idrobiol. 1975;32(Suppl.):37-59.

10. Wright JC, Westh P, Ramløv H. Cryptobiosis in Tardigrada. Biol Rev. 1992; 67(1):1-29. https://doi.org/10.1111/j.1469-185X.1992.tb01657.x

11. Bertolani R, Guidetti R, Jönsson Kl, Altiero T, Boschini D, Rebecchi L. Experiences with dormancy in tardigrades. J Limnol. 2004;63(1s):16-25. https://doi.org/10.4081/jlimnol.2004.s1.16.

12. Rebecchi L, Altiero T, Guidetti R. Anhydrobiosis: the extreme limit of desiccation tolerance. ISJ- Invert Surviv J. 2007:4:65-81.

13. Nelson DR, Guidetti R, Rebecchi L. Phylum Tardigrada. In: Thorp J, Rogers DC, editors. Ecology and General Biology: Thorp and Covich's Freshwater Invertebrates. Academic Press: Cambridge; 2015. p. 347-80. https://doi.org/1 0.1016/B978-0-12-385026-3.00017-6.

14. Nelson N, Bartels PJ, Guil N. In: Schill RO, editor. Water Bears: the biology of tardigrades. Springer: Berlin; 2018. p. 163-210. https://doi.org/10.1007/ 978-3-319-95702-9.

15. Schill RO, Hengherr S. Environmental adaptations: desiccation tolerance. In: Schill OR, editor. Water Bears: the biology of tardigrades. Springer: Berlin; 2018. p. 273-94. https://doi.org/10.1007/978-3-319-95702-9.

16. Møbjerg N, Jørgensen A, Kristensen RM, Neves RC. In: Schill RO, editor. Water Bears: the biology of tardigrades. Springer: Berlin; 2018. p. 57-94. https://doi.org/10.1007/978-3-319-95702-9. 
17. Hengherr S, Brummer F, Schill RO. Anhydrobiosis in tardigrades and its effects on longevity traits. J Zool. 2008;275(3):216-20. https://doi.org/1 0.1111/j.1469-7998.2008.00427.x.

18. Hibshman JD, Clegg JS, Goldstein B. Mechanisms of desiccation tolerance: themes and variations in brine shrimp, roundworms, and tardigrades. Front Physiol. 2020;11:592016. https://doi.org/10.3389/fphys.2020.592016.

19. Hesgrove $\mathrm{C}$, Boothby $\mathrm{TC}$. The biology of tardigrade disordered proteins in extreme stress tolerance. Cell Commun Signal. 2020;18(1):178. https://doi. org/10.1186/s12964-020-00670-2

20. Kamilari M, Jørgensen A, Schiøtt M, Møbjerg N. Comparative transcriptomics suggest unique molecular adaptations within tardigrade lineages. BMC Genomics. 2019;20(1):607. https://doi.org/10.1186/s12864-019-5912-x.

21. Bemm FM, Burleigh $L$, Foerster F, Schmucki R, Ebeling $M$, Janzen C, et al. Draft genome of the eutardigrade Milnesium tardigradum sheds light on ecdysozoan evolution. bioRxiv. 2017. https://doi.org/10.1101/122309.

22. Halberg KA, Jørgensen A, Møbjerg N. Desiccation tolerance in the tardigrade Richtersius coronifer relies on muscle mediated structural reorganization. PLoS One. 2013;8(12):e85091. https://doi.org/10.1371/journal. pone.0085091

23. Pigoń A, Węglarska B. Rate of metabolism in tardigrades during active life and anabiosis. Nature. 1955;176(4472):121-2. https://doi.org/10.1038/176121b0

24. Jönsson $\mathrm{Kl}$, Rebecchi $\mathrm{L}$. Experimentally induced anhydrobiosis in the tardigrade Richtersius coronifer: phenotypic factors affecting survival. J Exp Zool. 2002;293(6):578-84. https://doi.org/10.1002/jez.10186.

25. Tanaka S, Tanaka J, Miwa Y, Horikawa DD, Katayama T, Arakawa K, et al. Novel mitochondria-targeted heat-soluble proteins identified in the anhydrobiotic tardigrade improve osmotic tolerance of human cells. PLoS One. 2015;10(2):e0118272. https://doi.org/10.1371/journal.pone.0118272.

26. Rogov AG, Zvyagilskaya RA. Physiological role of alternative oxidase (from yeasts to plants). Biochem Mosc. 2015;80(4):400-7. https://doi.org/10.1134/ S0006297915040021

27. Vanlerberghe GC, Martyn GD, Dahal K. Alternative oxidase: a respiratory electron transport chain pathway essential for maintaining photosynthetic performance during drought stress. Physiol Plant. 2016;57(3):322-37. https:// doi.org/10.1111/ppl.12451.

28. McDonald $A E$, Gospodaryov DV. Alternative $N A D(P) H$ dehydrogenase and alternative oxidase: proposed physiological roles in animals. Mitochondrion. 2019:45:7-17. https://doi.org/10.1016/j.mito.2018.01.009.

29. Weaver RJ. Hypothesized evolutionary consequences of the alternative oxidase (AOX) in animal mitochondria. Integr Comp Biol. 2019;59(4):9941004. https://doi.org/10.1093/icb/icz015.

30. Moore AL, Albury MS. Further insights into the structure of the alternative oxidase: from plants to parasites. Biochem Soc Trans. 2008;36(5):1022-6. https://doi.org/10.1042/bst0361022.

31. Szibor M, Gainutdinov T, Fernandez-Vizarra E, Dufour E, Gizatullina Z Debska-Vielhaber, et al. Bioenergetic consequences from xenotopic expression of a tunicate AOX in mouse mitochondria: Switch from RET and ROS to FET. BBA-Bioenergetics. 2020;1861(2):148137. https://doi.org/10.1016/ j.bbabio.2019.148137.

32. McDonald AE, Vanlerberghe GC, Staples JF. Alternative oxidase in animals: unique characteristics and taxonomic distribution. J Exp Biol. 2009;212(16): 2627-34. https://doi.org/10.1242/jeb.032151.

33. Pennisi R, Salvi D, Brandi V, Angelini R, Ascenzi P, Polticelli F. Molecular evolution of alternative oxidase proteins: a phylogenetic and structure modeling approach. J Mol Evol. 2016;82(4-5):207-18. https://doi.org/10.1 007/s00239-016-9738-8.

34. Morek W, Suzuki A, Schill RO, Georgiev D, Yankova M, Marley N, et al. Redescription of Milnesium alpigenum Ehrenberg, 1853 (Tardigrada: Apochela) and a description of Milnesium inceptum sp. nov., a tardigrade laboratory model. Zootaxa. 2019;4586:35-64. https://doi.org/10.11646/zoota xa.4586.1.2.

35. Galganska H, Budzinska M, Wojtkowska M, Kmita H. Redox regulation of protein expression in Saccharomyces cerevisiae mitochondria: possible role of VDAC. Arch Biochem Biophys. 2008;479(1):39-45. https://doi.org/10.1016/ j.abb.2008.08.010.

36. Daum G, Gasse SM, Schatz G. Import of proteins into mitochondria. Energydependent, two-step processing of the intermembrane space enzyme cytochrome b2 by isolated yeast mitochondria. J Biol Chem. 1982;257(21): 13075-80. https://doi.org/10.1016/S0021-9258(18)33624-X.

37. Dastych H. Niesporczaki (Tardigrada) Tatrzańskiego Parku Narodowego. Monogr Fauny Pol. 1980;9:1-232.
38. Brenner S. The genetics of Caenorhabditis elegans. Genetics. 1974;77(1):71-94 https://doi.org/10.1093/genetics/77.1.71.

39. Zar JH. Biostatistical analysis. 5th ed. Prentice Hall: Northern Illinois University; 1999.

40. Sokal RR, Rohlp FJ. Biometry: the principles and practice of statistics in biological research. 3rd ed. New York: WH Freeman and Company; 1995.

41. R Core Team R. A language and environment for statistical computing. Vienna: R Foundation for Statistical Computing; 2013. http://www.R-project.org/

42. Robertson A, Schaltz K, Neimanis K, Staples JF, AE MD. Heterologous expression of the Crassostrea gigas (Pacific oyster) alternative oxidase in the yeast Saccharomyces cerevisiae. J Bioenerg Biomembr. 2016;48(5):509-20. https://doi.org/10.1007/s10863-016-9685-5.

43. Przychodzen W, Nycz JE, Nam Y-J, Lee D-U. Cytotoxic and antioxidant activities of benzohydroxamic acid analogues. Bull Kor Chem Soc. 2013;34:1. https://doi.org/10.5012/bkcs.2013.34.10.XXX

44. Adewuyi A, Otuechere CA, Oteglolade ZO, Bankole O, Unuabonah El. Evaluation of the safety profile and antioxidant activity of fatty hydroxamic acid from underutilized seed oil of Cyperus esculentus. J Acute Dis. 2015:4: 230-5. https://doi.org/10.1016/j.joad.2015.04.010.

45. Fernandez-Ayala DJ, Sanz A, Vartiainen S, Kemppainen KK, Babusiak M,

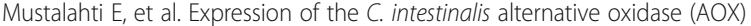
in Drosophila complements defects in mitochondrial oxidative phosphorylation. Cell Metab. 2009;9(5):449-60. https://doi.org/10.1016/j. cmet.2009.03.004

46. El-Khoury R, Dufour E, Rak M, Ramanantsoa N, Grandchamp N, Csaba Z, et al. Alternative oxidase expression in the mouse enables bypassing cytochrome c oxidase blockade and limits mitochondrial ROS overproduction. PLoS Genet. 2013;9(1):e1003182. https://doi.org/10.1371/ journal.pgen.1003182.

47. Szibor M, Dhandapani PK, Dufour E, Holmström KM, Zhuang Y, Salwig I, et al. Broad AOX expression in a genetically tractable mouse model does not disturb normal physiology. Dis Model Mech. 2017;10(2):163-71. https://doi. org/10.1242/dmm.027839.

48. Kemppainen KK, Rinne J, Sriram A, Lakanmaa M, Zeb A, Tuomela T, et al. Expression of alternative oxidase in Drosophila ameliorates diverse phenotypes due to cytochrome oxidase deficiency. Hum Mol Genet. 2014; 23(8):2078-93. https://doi.org/10.1093/hmg/ddt601.

49. Rajendran J, Purhonen J, Tegelberg S, Smolander OP, Mörgelin M, Rozman J, et al. Alternative oxidase-mediated respiration prevents lethal mitochondrial cardiomyopathy. EMBO Mol Med. 2019;11:e9456. https://doi.org/10.15252/ emmm.201809456.

50. Sussarellu R, Dudognon T, Fabioux C, Soudant P, Moraga D, Kraffe E. Rapid mitochondrial adjustments in response to short-term hypoxia and reoxygenation in the Pacific oyster, Crassostrea gigas. J Exp Biol. 2013;216(9): 1561-9. https://doi.org/10.1242/jeb.075879.

51. de Vries D, Marres CA. The mitochondrial respiratory chain of yeast. Structure and biosynthesis and the role in cellular metabolism. Biochim Biophys Acta. 1987;895(3):205-39. https://doi.org/10.1016/s0304-4173(87)80003-4.

52. Srinivasan S, Avadhani NG. Cytochrome c oxidase dysfunction in oxidative stress. Free Radic Biol Med. 2012;53(6):1252-63. https://doi.org/10.1016/j. freeradbiomed.2012.07.021.

53. Jönsson Kl. Radiation tolerance in tardigrades: current knowledge and potential applications in medicine. Cancers (Basel). 2019;11:1333. https://doi. org/10.3390/cancers11091333.

54. Saari S, Garcia GS, Bremer K, Chioda MM, Andjelković A, Debes PV, et al. Alternative respiratory chain enzymes: therapeutic potential and possible pitfalls. Biochim Biophys Acta Mol basis Dis. 1865;2019(4):854-66. https://doi. org/10.1016/j.bbadis.2018.10.012.

55. Rizzo AM, Altiero T, Corsetto PA, Montorfano G, Guidetti R, Rebecchi L. Space flight effects on antioxidant molecules in dry tardigrades: the TARDIKISS experiment. Biomed Res Int. 2015. https://doi.org/10.1155/2015/1 67642: 2015:1-7

56. Hermes-Lima M, Storey KB. Role of antioxidant defenses in the tolerance of severe dehydration by anurans. The case of the leopard frog Rana pipiens. Mol Cell Biochem. 1998;189(1/2):79-89. https://doi.org/10.1023/A:10068682 08476.

57. Murphy MP. How mitochondria produce reactive oxygen species. Biochem J. 2009:417(1):1-13.

58. Guidetti R, Jönsson Kl. Long-term anhydrobiotic survival in semi-terrestrial micrometazoans. J Zool (Lond). 2002;257(2):181-7. https://doi.org/10.1017/ S095283690200078X. 
59. Neumann S, Reuner A, Brümmer F, Schill RO. DNA damage in storage cells of anhydrobiotic tardigrades. Comp Biochem Physiol A Mol Integr Physiol. 2009;153(4):425-9.

60. Wright JC. Desiccation tolerance and water-retentive mechanisms in tardigrades. J Exp Biol. 1989;142:267-92.

61. Crowe J, Clegg J. Anhydrobiosis. Stroudsburg: Hutchinson \& Ross; 1973.

62. Kayes SM, Cramp RL, Hudson NJ, Franklin CE. Surviving the drought: burrowing frogs save energy by increasing mitochondrial coupling. J Exp Biol. 2009;212(14):2248-53.

63. Storey KB, Storey JM. Metabolic rate depression in animals: transcriptional and translational controls. Biol Rev Camb Philos Soc. 2004;79(1):207-33. https://doi.org/10.1017/s1464793103006195.

64. Letendre J, Leboulenger F, Durand F. Oxidative challenge and redox sensing in mollusks: effects of natural and anthropic stressors. In: Farooqui T, Farooqui AA, editors. Oxidative stress in vertebrates and invertebrates: Molecular aspects of cell signaling. New Jersey: Wiley-Blackwell; 2012. p. 361-76. https://doi.org/10.1002/9781118148143.ch7.

\section{Publisher's Note}

Springer Nature remains neutral with regard to jurisdictional claims in published maps and institutional affiliations.

Ready to submit your research? Choose BMC and benefit from:

- fast, convenient online submission

- thorough peer review by experienced researchers in your field

- rapid publication on acceptance

- support for research data, including large and complex data types

- gold Open Access which fosters wider collaboration and increased citations

- maximum visibility for your research: over $100 \mathrm{M}$ website views per year

At $\mathrm{BMC}$, research is always in progress.

Learn more biomedcentral.com/submissions 